\title{
SOCIAL SECURITY AND HOUSEHOLD WEALTH ACCUMULATION: NEW MICROECONOMETRIC EVIDENCE
}

\author{
Martin Feldstein and Anthony Pellechio*
}

T HE social security program will pay benefits of more than $\$ 100$ billion in $1978 .^{1}$ Public transfers on this scale are large enough to have profound effects on the behavior of the U.S. economy. The most important effect, although not the only one, is likely to be the impact of social security on private saving and aggregate capital accumulation. The present paper contributes to the analysis of this issue by providing new evidence on the extent to which the accumulation of wealth by individual households responds to differences in social security benefits.

\section{Social Security and Saving: The Theoretical Indeterminacy}

The traditional life cycle model implies that an actuarially fair social security program unambiguously reduces private saving. Within a more general framework, however, the effect of social security on saving is theoretically indeterminate. Only econometric evidence can determine the extent to which social security decreases saving. Before turning to our new evidence, it is worth examining the sources of the theoretical indeterminacy.

Consider first the effect of social security in the traditional life cycle model in which the time pattern of work and labor income is exogenously fixed. In this situation, social security can alter the time pattern of consumption only if it changes the household's lifetime budget constraint. Since

Received for publication December 23, 1977. Revision accepted for publication July 27, 1978.

* Harvard University and the National Bureau of Economic Research.

This research is part of the NBER program of Studies in Social Insurance. We are grateful to the NBER and the National Science Foundation for support of this research and to Robert Barro and participants in the Harvard social insurance seminar for helpful comments. This paper has not been reviewed by the NBER Board of Directors.

1 The social security program is technically three separate programs of old age and survivors insurance, disability insurance, and health insurance for the aged (Medicare). General retirement, survivors and disability benefits alone will exceed $\$ 100$ billion. an actuarially fair social security program leaves the budget constraint unchanged, there is also no change in each year's consumption. The social security tax that is paid each year therefore reduces private saving by an equal amount. For an actuarially fair social security program, this is equivalent to reducing the personal wealth accumulated before retirement by the actuarial present value of future benefits. ${ }^{2}$

It has been common in discussions of social security policy to reject this picture of rational life cycle saving. ${ }^{3}$ Individuals are instead viewed as myopic nonplanners who save in a haphazard way or not at all; as a result of such myopia, the introduction of social security would have no offsetting effect on private saving. ${ }^{4} \mathrm{We}$ agree that there are some individuals for whom this picture of irrational saving behavior is an appropriate description but we do not believe that such behavior is universal or even typical. Irrational saving behavior among part of the population would reduce the effect of social security on private saving but would not eliminate it. ${ }^{5}$ The econometric evidence presented below gives no support to the view that such irrationality is very widespread.

The extended life cycle model presented in Feldstein $(1974,1977)$ showed a quite different reason why individual life cycle saving might not be decreased and might actually be increased by the introduction or increase of social security benefits. The essential feature of the extended life cycle model is that retirement and saving decisions are made jointly. Any exogenous vari-

\footnotetext{
${ }^{2}$ The result is shown graphically for the two-period life cycle model in Feldstein (1974) and derived explicitly in Feldstein (1977).

${ }^{3}$ See, for example, Myers (1965), Pechman et al. (1968), Schulz (1974), and Diamond (1977).

${ }^{4}$ Some have even suggested that the provision of social security may actually cause some individuals to save more because it serves as a reminder of the need to provide for old age. See Katona (1965) and Pechman et al. (1968).

5 The irrational saving behavior of a small fraction of the population might justify a compulsory saving program even if it had a small aggregate effect on saving. This is a quite separate question that will not be examined in this paper.
} 
able can thus influence saving indirectly by altering retirement. Social security is likely to induce earlier retirement and the resulting increase in the expected period of retirement will, as such, increase total saving during preretirement years. The net effect of social security on saving in this extended life cycle model is ambiguous. Whether and to what extent social security reduces saving depends on the relative strength of the traditional "wealth replacement effect" and the countervailing "induced retirement effect."'6

Even if we disregard the effect of social security on retirement, there are at least four reasons why rational savers might not regard social security wealth and private fungible wealth as perfect substitutes. ${ }^{7}$ First, social security provides an annuity rather than a fixed sum at retirement and, even before price indexing was formally incorporated, adjusted benefits for rising prices. Because of this "real annuity" character of social security, individuals might reasonably regard a dollar of social security wealth as a substitute for more than a dollar's worth of fungible assets. Second, social security benefits are not a contractual obligation of the government but are determined by legislation. ${ }^{8}$ Pessimists might therefore underestimate the value of social security wealth while optimists overestimate it. Third, social security is not an actuarially fair program, but alters lifetime budget constraints; such changes in real lifetime resources will alter consumption and saving. ${ }^{9}$ Fourth, the introduction of social security (or a change in an existing program) may cause offsetting changes in private intergenerational transfers, thereby reducing the depressing effect of social security on private saving. ${ }^{10}$

\footnotetext{
6 See Feldstein (1977) for a formal derivation of this.

7 We define "social security wealth" as the present actuarial value of future social security benefits. The adjective "fungible" is used to distinguish household wealth as traditionally defined from the total household wealth. The calculation of social security wealth is discussed in section III below and in Feldstein (1974).

${ }^{8}$ Until 1972 the law made no provision for future increases in the schedule of social security benefits. Increases occurred frequently, but required explicit acts of Congress.

9 This important aspect is developed in Kotlikoff et al. (1977).

10 This idea is developed by Barro (1974) and Miller and Upton (1974). Our econometric evidence deals only partially with this issue. In particular, our evidence does not preclude the possibility that the existence of social security tax liabilities on future generations could cause every household to raise its savings while the existence of benefits for the current generation of workers causes differential reduction in
}

In this paper, we analyze a cross section of households and find that differences in future social security benefits cause differences in ordinary saving. It should go without saying that no single econometric study can ever be conclusive. The current research should be seen as an addition to a growing body of new evidence on the effect of social security on the accumulation of wealth. ${ }^{11}$

\section{The Econometric Specification}

The present study uses individual household observations to estimate the effect of social security on the amount of wealth that individuals accumulate by the end of the normal working life. The specification of our econometric equation focuses on the stock of accumulated wealth rather than the annual flow of saving. The current section discusses our specification and the interpretation of the parameters in more detail.

It is useful to begin with the relation between labor income and accumulated individual wealth that is predicted by the traditional life cycle model in the absence of any social security. In its most general form, the traditional life cycle model implies only that each individual accumulates wealth during his working years to finance consumption during retirement; further restrictions are needed to specify an econometric equation. Under the assumption that all individuals have the same tastes with respect to consumption at different ages, that each individual's netof-tax labor income has its own level but grows at the same exponential rate, and that intended bequests are either nonexistent or proportional to the present value of the individual's labor income, the traditional life cycle model implies that in any age cohort the value of each individual's

savings. The direct evidence on the value of bequests by low and middle income families is, however, contrary to the prediction of the Barro-Miller-Upton theory. For a more detailed discussion of the reasons for believing that the effects of offsetting intergenerational transfers is quantitatively small, see Feldstein (1978). For those who remain agnostic about the magnitude of offsetting bequests, our evidence can be interpreted as quantifying the extent to which other reasons cause a departure from the complete replacement predicted by the traditional life cycle model.

11 The studies to date include analyses of time series evidence (Feldstein, 1974; Munnell, 1974; Barro, 1978; Darby, 1979), household survey data (Feldstein, 1976a; Kotlikoff et al., 1977; Munnell, 1976), and cross-country data on national savings rates (Aaron, 1967; Feldstein, 1977). A brief survey of the available estimates is presented in Feldstein (1976b). 
accumulated wealth is related by a unique function to his current net labor income. It has also been traditional to assume that this functional relation is one of proportionality. Consumption during retirement is then proportional to the level of consumption during the earlier working years. This implies further that the value of accumulated wealth on the verge of retirement is proportional to that final year's earnings.

Social security provides each individual with an annuity when he retires. In the traditional life cycle model, the present value of that annuity should substitute for an equal amount of private wealth at the time of retirement. The model therefore implies that each individual's desired accumulation of "total wealth" including "social security wealth" will be proportional to his final year's net labor income:

$$
\frac{A_{i}+S S W_{i}}{Y L_{i}}=\alpha_{1}
$$

where $A_{i}$ is the value of individual $i$ 's ordinary "fungible" wealth on the verge of retirement, $S S W_{i}$ is the social security wealth (the present actuarial value of the benefits to be provided by social security), and $Y L_{i}$ is the net-of-tax labor income in the final preretirement year.

The extended life cycle model begins with the basic fact that the age of retirement is an endogenous variable. The value of social security wealth at some age at which retirement might be contemplated (say, age 60) will influence the individual's retirement decision. ${ }^{12}$ This implies that the total wealth desired at age 60 will itself be a function of $S S W$ relative to $Y L$ :

$$
\frac{A_{i}+S S W_{i}}{Y L_{i}}=\alpha_{1}+\alpha_{2} \frac{S S W_{i}}{Y L_{i}} \text {. }
$$

Since a higher value of $S S W / Y L$ induces earlier retirement and therefore a larger desired stock of total wealth, the extended life cycle model implies $\alpha_{2}>0$.

The proportionality assumption can be relaxed to allow the possibility that the ratio of total retirement consumption to consumption during working years is a function of the individual's net labor income. This can be approximated linearly by replacing (2) by

\footnotetext{
12 Recall that benefits are paid only to individuals who are essentially retired.
}

$$
\frac{A_{i}+S S W_{i}}{Y L_{i}}=\alpha_{1}+\alpha_{2} \frac{S S W_{i}}{Y L_{i}}+\alpha_{3} Y L_{i}
$$

where $\alpha_{3}>0$ if higher earnings induce a redistribution of lifetime income in favor of older age. ${ }^{13}$ Multiplying both sides of (3) by $Y L_{i}$ yields the basic specification that will be used in our econometric analysis:

$$
A_{i}+S S W_{i}=\alpha_{1} Y L_{i}+\alpha_{2} S S W_{i}+\alpha_{3} Y L_{i}^{2}
$$

This specification can be modified easily to allow for the possibility that social security induces changes in gifts from children to their retired parents.

If children reduce their gifts to their parents in proportion to the parents' receipt of social security benefits, the value of the social security wealth is reduced; total wealth should be written $A_{i}+\left(1-\alpha_{4}\right) S S W_{i}$ rather than $A_{i}+S S W_{i} \cdot{ }^{14}$ Even if the induced changes in gifts from children to parents are ignored, we may wish to allow for a difference between $S S W$ and ordinary assets because of such things as the real annuity character of social security or its non-contractual character. This suggests replacing $S S W_{i}$ in (4) by some multiple of $S S W_{i}$, say $\lambda S S W_{i}$, where $\lambda$ may be either less than or greater than 1 but is not expected to differ from 1 by very much.

Combining all of these effects yields the specification 15

$$
\begin{aligned}
A_{i}+\left(1-\alpha_{4}\right) \lambda S S W_{i}= & \alpha_{1} Y L_{i}+\alpha_{2} \lambda S S W_{i} \\
& +\alpha_{3} Y L_{i}^{2}
\end{aligned}
$$

or, collecting terms,

$$
A_{i}=\alpha_{1} Y L_{i}-\mu S S W_{i}+\alpha_{3} Y L_{i}^{2}
$$

where

$$
\mu=\left(1-\alpha_{2}-\alpha_{4}\right) \lambda \text {. }
$$

Thus, the traditional life cycle model implies $\mu=$ 1 , while the effects of induced retirement $\left(\alpha_{2}\right)$

${ }^{13}$ Feldstein (1977) presents evidence that the higher saving rate associated with higher income levels in cross-country data is really a reflection of the fact that retirement generally occurs earlier in higher income countries.

${ }_{14}$ The effect of $S S W$ on retirement implied by $\alpha_{2} S S W$ might also be changed to $\alpha_{2}\left(1-\alpha_{4}\right) S S W$, but this implies a particular and perhaps less plausible behavior of parents. The two specifications are empirically indistinguishable with the current data.

${ }^{15}$ One might argue for $\lambda-\alpha_{4}$ instead of $\left(1-\alpha_{4}\right) \lambda$ but the distinction is essentially nonoperational. 
and offsetting child-parent gifts $\left(\alpha_{4}\right)$ reduce this value. The other factors included in $\lambda$ could either lower or raise $\mu$. Thus, $\mu>1$ cannot be precluded if, for example, there is little effect through induced early retirement or changes in intergenerational transfers but there is substantial optimism about the size of benefits or a great premium placed on the real annuity character of social security.

It is, of course, unfortunate that the estimation of an equation like (6) cannot identify the relative importance of each of the parameters in (7). An estimate of $\mu$ is sufficient to answer the policyrelated question about the net effect of social security on private saving but knowledge of the individual parameters in (7) is required to evaluate the competing theories of behavior that were discussed in the preceding section. Although such individual parameter estimates cannot be obtained, the value of $\mu$ can be used to assess some of the extreme versions of these theories. For example, the pure traditional life cycle model implies $\mu=1$ while complete myopia and irrationality implies $\mu=0$. Similarly, completely offsetting changes in gifts from children to parents $\left(\alpha_{4}=1\right)$ imply $\mu \leq 0$. The estimated value of $\mu$ can therefore in principle help to reduce the range of admissible theories about saving behavior.

The use of a two-year average value of $Y L$ to represent a lifetime history of net earnings and of bequests and gifts received rests on the formal assumption that net earnings grow exponentially and that all other receipts are proportional to labor income. Because we are limited by the available data to only a two-year average for $Y L_{i}$, we add a random error and a constant term to equation (6) to indicate that (6) cannot be expected to hold precisely:

$$
A_{i}=\alpha_{0}+\alpha_{1} Y L_{i}-\mu S S W_{i}+\alpha_{3} Y L_{i}^{2}+u_{i} .
$$

This is the final estimation equation used in our econometric analysis. It should be emphasized that our sample will be limited to households with men between the ages of 55 and 64 so that $A_{i}$ represents fungible wealth on the verge of the normal retirement age. The sample will also be restricted in other ways that will be described in the next section.

In concluding this section, it is worthwhile to note that equation (8) avoids a very substantial bias that has been a source of serious trouble in previous tests of the traditional life cycle model based on household data. ${ }^{16}$ The standard form of such tests has been to estimate a saving equation with a lagged wealth variable among the regressors and observe whether its coefficient is negative. ${ }^{17}$ Since the most important source of unexplained variation among households (the $u_{i}$ 's of equation (8)) reflects permanent differences in taste and in risk aversion, the disturbance in a saving equation will be positively correlated with the lagged wealth variable. This is likely to cause a substantial bias that can account for the apparently poor performance of the life cycle hypothesis in previous cross-section tests. Because the current study focuses on the equilibrium stock of wealth rather than the annual savings flow and uses an exogenous variable $(S S W)$ instead of a lagged endogenous variable, this potential source of substantial bias is avoided.

\section{Data and Definitions}

The data used in the present research were collected in the Federal Reserve Board's Survey of Financial Characteristics of Consumers (Projector and Weiss, 1966) in which detailed balance sheets and income statements were obtained from all participants. The survey was conducted in 1963 and refers to income in 1962 and wealth at the end of 1962. A follow-up survey obtained data on income in 1963. The present study uses the subsample of households in which there was an employed man aged 55 to 64 who was covered by social security. Households with very low incomes (less than half of the median) and very high incomes (more than 2.5 times the maximum covered by social security) were eliminated as were those reporting substantial bequests. ${ }^{18}$

The dependent variable $(A)$ that we have used corresponds as closely to household net worth as is possible with the available data. Labor income $(Y L)$ is defined to include all income other than income from property. It is the average of the sum of wage and salary income, income from

\footnotetext{
${ }^{16}$ See Projector and Weiss (1966), Modigliani and Ando (1957), and, more generally, the survey of studies reported in Mayer (1972).

${ }_{17}$ Alternatively a consumption function is estimated and a positive coefficient is expected on the lagged wealth variable.

${ }^{18}$ For more details of the sample, see section III of Feldstein and Pellechio (1977).
} 
sole proprietorships, and farm income in 1962 and 1963. The amount paid in income taxes for the two years is estimated and subtracted from total income from these sources to give disposable labor income.

The value of social security wealth was evaluated for each observation in this sample. By definition, an individual's social security wealth is the value of the benefits for which he will be eligible at age 65 less the taxes he will pay until then, discounted to the present with appropriate adjustment for actuarial survival probabilities. A married couple's social security wealth is defined in an analogous way. The survey data on the separate earnings of the husband and wife and on their ages can be used to estimate the couple's social security wealth. The procedure has been described in detail elsewhere (Feldstein, 1976a). ${ }^{19}$

Before turning to the econometric estimation of the wealth accumulation equation, it is important to recall some of the limitations of the current data. First, we have no information on either private pensions or life insurance. Our measure of household assets therefore understates true net worth and this understatement is likely to be an increasing function of income and perhaps of social security wealth as well. To the extent that households substitute private pensions and life insurance for other forms of asset accumulation, the regression estimates will understate the effects of income on asset accumulation and overstate the effect of social security. These biases are likely to be relatively small because pension coverage was relatively poor for this age cohort of men (born in the decade from 1898 to 1907). Second, the labor income variable bases an estimate of lifetime earnings on information for only two years. Although this would be appropriate if each individual's earnings grew exponentially, there is in fact substantial variation in earnings from year to year. To the extent that this introduces random measurement error in the estimate of both $Y L$ and $S S W$, their coefficients will be

\footnotetext{
${ }^{19}$ A full description of the current method is described in Feldstein and Pellechio (1977); see especially the appendix. There are a number of technical improvements over the method used in Feldstein (1976a) but these do not alter the general logic of the calculation presented there. The definition used here corresponds to the net social security variable (NSSW1) in Feldstein (1974) but the disaggregated data permit the use of more detailed information.
}

biased; since the measurement errors are correlated with each other and the two values of $Y L$ and $S S W$ are also correlated with each other, the direction of the bias cannot be determined without further information. Finally, it should be remembered that the data refer to 1963 when the social security program was much smaller and newer than it is today; the response of individuals at that time cannot be extrapolated to the present without considering the changes that have occurred during the past 15 years.

\section{The Parameter Estimates}

The basic parameter estimates presented in this section imply that social security substantially reduces the accumulation of household wealth as traditionally defined. More specifically, the point estimates generally indicate that each dollar of social security wealth reduces fungible net worth by somewhat less than one dollar. The standard errors are too large to reject the implication of the traditional life cycle model that there is dollar-for-dollar replacement, but the estimates are also consistent with a rather wide range of other replacement rates. In general, however, the estimates are incompatible with the hypothesis that differences among households in social security wealth have no net effect on private wealth accumulation.

Before looking at the parameter estimates, it is useful to examine some characteristics of the sample and of the population that it represents. Our final sample contains 126 married couples plus 12 additional households with a man who was not married at the time of the survey. The sampling probabilities imply that these observations represent 4.5 million couples and a total of 4.9 million households. The mean net worth of these 4.9 million households (as of the end of 1962) was $\$ 20,801$ and the corresponding standard deviation was $\$ 32,054$. Their average labor income was $\$ 5,555$ with a standard deviation of $\$ 2,806$; median family income (including nonlabor income) for the entire U.S. population was then $\$ 6,100$. Traditional net worth thus averaged about four times income. The average value of social security wealth was $\$ 24,017$, about as large as all other household wealth; the standard deviation was $\$ 7,709$. Finally, the men in the group had an average age of 59 years and $89 \%$ were 
married. The means and standard deviations of the income, wealth, and age variables are essentially unchanged if attention is limited to couples only.

The estimates presented below can be classified in two ways. First, separate estimates are presented for married couples and for all households. The results for the sample with only married couples are more reliable because the group of single men probably includes men who recently became widowers but who had accumulated wealth to support a couple in retirement. Combining couples and single men also raises the difficult problem of comparing the life cycle saving patterns of individuals and couples. Nevertheless, estimates for all households are presented in order not to restrict the sample unnecessarily; the combined estimates are not substantially different from the estimates for couples only.

Second, each equation is estimated with the unweighted sample of observations and with the sample weighted by the inverse of the sampling probabilities. Weighting in this way gives more weight to the middle income families around and below the maximum social security earnings and less to the higher income families. If the equation parameters are not fixed numbers but vary among individuals in a way that is related to income, the coefficients derived in the weighted regressions are more appropriate as measures of the relevant average behavior of the population. Moreover, since the sampling probabilities were an increasing fraction of income, the method of weighting is likely to produce estimates that are statistically more efficient by reducing the problem of heteroscedasticity that arises because the variance in the error of the household assets equation is an increasing function of income.

Equation 1 of table 1 implies that each extra dollar of social security wealth reduces the accumulation of ordinary fungible net worth by 93e. The standard error of the coefficient $(0.42)$ and the caveats about the variables themselves that were noted in section III should both caution against giving too much weight to this or any other specific point estimate in table 1 . Instead, these estimates must be seen collectively and as a part of the accumulating body of evidence based on quite different types of data.

Table 1.-Effects of Social Security Wealth on Household Asset Accumulation

\begin{tabular}{|c|c|c|c|c|c|c|c|c|c|}
\hline Equation & Weight ${ }^{\mathrm{a}}$ & Married $^{b}$ & $S S W$ & $Y L$ & $(Y L)^{2} \times 10^{-3}$ & $A Y L$ & $M Y L$ & Constant & $\bar{R}^{2}$ \\
\hline 1 & $\mathbf{U}$ & Mar & $\begin{array}{c}-0.93 \\
(0.42)\end{array}$ & $\begin{array}{c}3.49 \\
(0.70)\end{array}$ & & & & $\begin{array}{c}25,100 \\
(10,600)\end{array}$ & .158 \\
\hline 2 & W & Mar & $\begin{array}{c}-1.26 \\
(0.34)\end{array}$ & $\begin{array}{c}2.93 \\
(0.79)\end{array}$ & & & & $\begin{array}{l}35,270 \\
(8,840)\end{array}$ & .132 \\
\hline 3 & $\mathbf{U}$ & Mar & $\begin{array}{c}-0.72 \\
(0.44)\end{array}$ & $\begin{array}{c}-1.16 \\
(3.03)\end{array}$ & $\begin{array}{c}0.29 \\
(0.18)\end{array}$ & & & $\begin{array}{c}34,920 \\
(12,200)\end{array}$ & .168 \\
\hline 4 & W & Mar & $\begin{array}{c}-0.69 \\
(0.34)\end{array}$ & $\begin{array}{c}-9.56 \\
(2.74)\end{array}$ & $\begin{array}{c}0.86 \\
(0.18)\end{array}$ & & & $\begin{array}{l}57,140 \\
(9,380)\end{array}$ & .261 \\
\hline 5 & $\mathbf{U}$ & Мar & $\begin{array}{c}-0.96 \\
(0.46)\end{array}$ & $\begin{array}{c}2.06 \\
(7.05)\end{array}$ & & $\begin{array}{c}0.025 \\
(0.123)\end{array}$ & & $\begin{array}{c}25,870 \\
(11,300)\end{array}$ & .151 \\
\hline 6 & W & Mar & $\begin{array}{c}-1.12 \\
(0.36)\end{array}$ & $\begin{array}{l}12.01 \\
(7.89)\end{array}$ & & $\begin{array}{c}-0.160 \\
(0.138)\end{array}$ & & $\begin{array}{l}33,350 \\
(8,990)\end{array}$ & .134 \\
\hline 7 & $\mathbf{U}$ & Mar & $\begin{array}{c}-0.72 \\
(0.49)\end{array}$ & $\begin{array}{c}-0.99 \\
(7.28)\end{array}$ & $\begin{array}{c}0.29 \\
(0.19)\end{array}$ & $\begin{array}{c}-0.003 \\
(0.123)\end{array}$ & & $\begin{array}{c}34,840 \\
(12,600)\end{array}$ & .161 \\
\hline 8 & w & Mar & $\begin{array}{c}-0.58 \\
(0.36)\end{array}$ & $\begin{array}{c}-1.66 \\
(7.84)\end{array}$ & $\begin{array}{c}0.85 \\
(0.18)\end{array}$ & $\begin{array}{c}-0.137 \\
(0.128)\end{array}$ & & $\begin{array}{l}55,310 \\
(9,530)\end{array}$ & .261 \\
\hline 9 & $\mathbf{U}$ & All & $\begin{array}{c}-0.86 \\
(0.79)\end{array}$ & $\begin{array}{c}7.84 \\
(5.40)\end{array}$ & $\begin{array}{c}0.05 \\
(0.33)\end{array}$ & & $\begin{array}{c}-5.26 \\
(2.90)\end{array}$ & $\begin{array}{c}26,880 \\
(20,200)\end{array}$ & .151 \\
\hline 10 & W & All & $\begin{array}{c}-0.51 \\
(0.45)\end{array}$ & $\begin{array}{c}-4.83 \\
(3.51)\end{array}$ & $\begin{array}{c}0.73 \\
(0.24)\end{array}$ & & $\begin{array}{c}-2.54 \\
(2.11)\end{array}$ & $\begin{array}{c}44,770 \\
(11,200)\end{array}$ & .131 \\
\hline 11 & $\mathrm{U}$ & All & $\begin{array}{c}-1.67 \\
(0.65)\end{array}$ & $\begin{array}{c}5.45 \\
(5.28)\end{array}$ & $\begin{array}{c}-0.10 \\
(0.32)\end{array}$ & & & $\begin{array}{c}38,470 \\
(19,300)\end{array}$ & .081 \\
\hline 12 & W & All & $\begin{array}{c}-0.82 \\
(0.37)\end{array}$ & $\begin{array}{c}-5.86 \\
(3.41)\end{array}$ & $\begin{array}{c}0.64 \\
(0.23)\end{array}$ & & & $\begin{array}{c}48,480 \\
(10,700)\end{array}$ & .128 \\
\hline
\end{tabular}

Note: The dependent variable in all equations is household net worth (excluding social security wealth). Standard errors are shown in parentheses.

" $U$ indicates unweighted regression; $W$ indicates regression weighted by inverse sampling probabilities.

- Equations 1 through 8 are restricted to the sample of married couples. 
Equation 2 repeats the same specification as equation 1 but with the observations weighted by the inverses of the sampling probabilities. The coefficient of $S S W$ becomes somewhat larger than 1 but again the standard error cautions against focusing on the specific point estimate. The homotheticity assumption is dropped and a quadratic income term is added in equations 3 and 4 . The estimated coefficients of the social security wealth variables are now reduced to about 0.70 ; by the usual formal criteria, the coefficients are significantly different from zero but not significantly different from one.

Although the sample is restricted to men aged 55 to 64 , it is possible that variations in age within this range affect the accumulation of wealth. Our failure to take this into account could in principle be a source of bias in the remaining coefficients. Age can affect the accumulation of wealth in a rather complex way. The life cycle theory implies that, because older men generally have worked longer and are closer to retirement, net worth shall increase with an individual's age. However, the relation between wealth and age for a cross section of individuals should not be the same as it is over time for a single individual or birth cohort. Even within the group of men aged 55 to 64, such events as the Depression and World War II came at very different ages and therefore could be expected to have different effects on life cycle saving. For example, the older men were in their early thirties when the Depression began while the younger men were just in their early twenties; the resulting reduction in lifetime saving can therefore be expected to be greater in the older age group. Equations 5 through 8 make a crude adjustment for the effect of age by making the equilibrium ratio of wealth to income ( $\alpha_{1}$ of equation (1)) a linear function of age. This is equivalent to adding a variable to the equation that is the product of the individual's age and labor income; $A Y L=A G E \times Y L$. The estimates in equations 5 through 8 show no statistically significant effect of age and no substantial effect on the coefficient of $S S W$ of including the age-income variable.

Equations 9 through 12 drop the restriction of the sample to married couples and reestimate the basic specification with the quadratic income term. In the first two of these equations, a separate adjustment is made by adding a variable ( $M Y L$ ) that is equal to $Y L$ for a married couple but otherwise equal to zero; this is equivalent to allowing a different equilibrium wealth-income ratio in equation (1) (i.e., a different value of $\alpha_{1}$ ). Equations 9 and 10 have the surprising implication that couples accumulate less wealth than single individuals, but the standard errors are large relative to the coefficients. ${ }^{20}$ The estimated effects of $S S W$ are generally similar to the coefficients for married couples only.

In the notation of equations (7) and (8) the coefficient of the social security wealth variable is $\mu=\left(1-\alpha_{2}-\alpha_{4}\right) \lambda$, where (1) an induced retirement effect of social security on saving implies $\alpha_{2}>0$, (2) induced changes in child-toparent transfers that tend to offset the effect of social security imply $\alpha_{4}>0$, and (3) such differences between social security wealth and ordinary wealth as fungibility and inflation protection imply $\lambda \neq 1$. The estimates of $\mu$ approximately equal to 1 and significantly different from 0 indicate that it is very unlikely that social security induces changes in either child-to-parent transfers or retirement plans that substantially negate the direct effect of social security on savings. The specific combination of $\alpha$ 's and $\lambda$ corresponding to the estimated value of $\mu$ obviously cannot be identified on the basis of the available evidence.

\section{Conclusion}

In conclusion, we wish only to reiterate that the parameter estimates presented in this paper should not be seen in isolation but as part of a larger body of evidence on life cycle savings behavior in general and on the effects of social security on saving in particular. We are as conscious as anyone of the limitations of the current data and of the problems of interpreting our results. We believe, however, that the current estimates do support the validity of the life cycle approach and of the specific conclusion that social security significantly depresses private wealth accumulation. Significant improvements in microeconometric analysis of this question must await the development of data combining accurate records of lifetime earnings, social security wealth, and private net worth.

\footnotetext{
20 The difference between couples and single individuals may also reflect the role of life insurance.
} 
REFERENCES

Aaron, Henry J., "Social Security: International Comparison," in Otto Eckstein (ed.), Studies in the Economics of Income Maintenance (Washington, D.C.: The Brookings Institution, 1967), 13-48.

Barro, Robert, "Are Government Bonds Net Wealth?" Journal of Political Economy 82 (Nov./Dec. 1974), $1095-1117$

"Social Security and Private Saving-Evidence from the U.S. Time Series,"' in Studies in Social Security and Retirement Policy, American Enterprise Institute, 1978.

Darby, Michael, "The Effects of Social Security on Income and the Capital Stock," mimeographed, American Enterprise Institute, 1979.

Diamond, Peter, "A Framework for Social Security Analysis," Journal of Public Economics 8 (Dec. 1977), 275-298.

Feldstein, Martin, "'Social Security, Induced Retirement, and Aggregate Capital Accumulation," Journal of Political Economy 82 (Sept./Oct. 1974), 905-926.

_- "Social Security and the Distribution of Wealth," Journal of the American Statistical Association 71 (Dec. 1976a), 800-807.

- "Social Security and Saving: The Extended Life Cycle Theory,'” American Economic Review 66 (May 1976b), 77-86.

"Social Security and Private Savings: International Evidence in an Extended Life Cycle Model," in Martin Feldstein and Robert Inman (eds.), The Economics of Public Services, an International Economic Association Conference Volume (New York: Halsted Press, 1977).

-, "Social Security and Private Savings: Reply to Barro," in Studies in Social Security and Retirement Policy, American Enterprise Institute, 1978.

Feldstein, Martin, and Anthony Pellechio, "Social Security and Household Wealth Accumulation: New Mi- croeconometric Evidence," National Bureau of Economic Research Discussion Paper No. 206, 1977.

Katona, George, Private Pensions and Individual Saving, Survey Research Center, Institute for Social Research, The University of Michigan, 1965.

Kotlikoff, Larry, Anthony Pellechio, and Christophe Chamley, "Social Security and Private Wealth Accumulation," mimeographed, Harvard University, 1977.

Mayer, Thomas, Permanent Income, Wealth, and Consumption: A Critique of the Permanent Income Theory, the Life-Cycle Hypothesis, and Related Theories (Berkeley: University of California Press, 1972).

Miller, M. H., and C. W. Upton, Macroeconomics: A Neoclassical Introduction (Homewood, Illinois: Irwin Publishing Company, 1974).

Modigliani, Franco, and Albert Ando, "Tests of the LifeCycle Hypothesis of Savings," Bulletin of the Oxford University Institute of Statistics 19 (May 1957), 99124.

Munnell, Alicia H., The Effect of Social Security on Personal Savings (Cambridge: Ballinger Publishing Company, 1974).

_-, "Private Pensions and Saving: New Evidence," Journal of Political Economy 84 (Oct. 1976), 10131032.

Myers, Robert J., Social Insurance and Allied Government Programs (Homewood, Illinois: Richard D. Irwin, 1965).

Pechman, Joseph A., Henry J. Aaron, and Michael K. Taussig, Social Security: Perspectives for Reform (Washington, D.C.: The Brookings Institution, 1968).

Projector, Dorothy S, and Gertrude S. Weiss, Survey of Financial Characteristics of Consumers (Washington, D.C.: Board of Governors of the Federal Reserve System, 1966).

Schulz, James, et al. Providing Adequate Retirement Income: Pension Reform in the United States and Abroad (Hanover, New Hampshire: Published for Brandeis University Press by the University Press of New England, 1974). 